\title{
Investigation on Mutual Coupling of Aperture Coupled Cylindrical Dielectric Resonator Antenna (DRA)
}

\author{
Segar Rajamanickam ${ }^{1}$, Rasammal Rasappan ${ }^{2}$, Noazri Bin Bakhari ${ }^{3}$ \\ ${ }^{1}$ Electrical Department, Politeknik Seberang Perai, 13500 Permatang Pauh, Penang, Malaysia. \\ email: vgsegar@psp.edu.my \\ ${ }^{2}$ Mathematcs,Science and Computer Department, Politeknik Balik Pulau, 6, Pinang Nirai Mukim, Kampung \\ Permatang Tengah, 11000 Balik Pulau, Pulau Pinang \\ email: rasammal02@hotmail.com \\ ${ }^{3}$ Electrical Department, Politeknik Seberang Perai, 13500 Permatang Pauh, Penang, Malaysia. \\ email: azri@psp.edu.my
}

\begin{abstract}
In this research, study on mutual coupling of aperture coupled cylindrical DRA and its influence on return loss, radiation pattern including the directivity, gain and bandwidth was computed and illustrated. The DRA was excited by a micro strip line with aperture coupled slots where the slot locations were calculated using the characteristic of standing wave ratio over a short ended micro strips. Small dielectric resonator antenna was designed using high permittivity dielectric material with permittivity the substrate of 3.38. The diameter of the dielectric resonator is $12 \mathrm{~mm}$ with the height of $4.2 \mathrm{~mm}$. The element spacing that been investigated for the effect of mutual coupling was at $0.5 \lambda, 0.75 \lambda$ and $1 \lambda$ with maximum of four DRA been used. The final result shows the effect of mutual coupling is decreased with three DRA element with the gain measured at 5.948GHz frequency is about $\mathbf{8 . 6 1 9 d B}$ with high directivity measured at $11.4 d B i$. This shows that the proposed DRA with three $1 \lambda$ spacing DRA elements exhibits an enhancement of the gain and directivity in comparison with a single pellet DRA. Hence, by increasing the level of isolation between the two identical DRAs to $1 \lambda$ it actually helps electromagnetic interaction to attract and further increase the directivity and effective area.
\end{abstract}

Key words: Antenna, DRA, Electromagnetic, Mutual Coupling

\section{INTRODUCTION}

Revolutionary growth in the last decade in telecommunication system particularly in wireless technology has caused necessity for the miniaturization of microwave circuits [1]. This contributes to the development of second-generation (2G) mobile telephone using digital technology and encouraged the development of wideband third-generation (3G) cellular phone [2] This technology is used for other wireless products and services, such as wireless local area networks (WLAN), Bluetooth, Wireless Bridge, WiMax, RADAR, Wireless Sensor, home RF, Global Positioning System and wireless local loops. Antenna is the basic fundamental component of a wireless device which plays an important role in transmitting and receiving signal [3].

Therefore the need in developing a highly efficient, low-profile, large bandwidth capabilities and small size antenna that can be imbedded into wireless products is important [4,5]. Dielectric Resonator Antenna (DRA) exhibits all the above mentioned criteria for present technology growth in electronic systems operating in the RF and the microwave spectrum[6].

\section{LITERATURE REVIEW}

DRA also has negligible ohmic losses which is mainly due to imperfect dielectric materials and ohmic loss occurring due to feeding mechanism and ground plane current, high radiation efficiency and increased bandwidth can be achieved with lower permittivity, 
where for a simple rectangular DRA, a bandwidth of $10 \%$ can be achieved for a dielectric constant of 10 or less [1]. So far DRA has been designed to be used over a wide range of frequencies and wide range of dielectric constants. [7]. When a dielectric resonator is not entirely enclosed by a conductive boundary, it can radiate and that is when it becomes an antenna. DRAs are commonly low gain antennas with a broad radiation pattern. DRAs can be designed in three basic shapes such as hemispherical, cylindrical and rectangular. Resonant Modes: - Dielectric resonators are difficult to analyse as they have complex electromagnetic problems. It was found that the resonant frequencies are complex valued [8]. Array Elements: - is a low gain and broad radiation is the typical characteristic of DRAs. Higher gain and shaped radiation pattern can be achieved with arrayed DRAs. The DRA elements can be used to form DRA array with directional radiation patterns providing enhanced antenna gain for broadband satellite communications and radar application. Mutual coupling (MC) or isolation: - is a term that describes the electromagnetic wave (EMW) interaction between antennas placed in closed proximity [2]. This interaction causes some consequences on the antennas' characteristic including distortion of radiation pattern of the array, input impedance, and gain, operating frequency, bandwidth and efficiency [9].

\section{DIELECTRIC RESONATOR ANTENNA}

DRAs were designed using low-loss and high relative dielectric material which when excited at certain frequencies, the dielectric resonators can be made to radiate very efficiently [10].The energy stored in dielectric materials is very high and any other external objects cannot disturb the resonance of this material. DRA comes in different shapes, several feeding mechanism and features many advantages. The advantages are in terms of smaller size through the use of higher permittivity, since the guided wavelength is inversely proportional to the permittivity of the dielectric material. DRA also has negligible ohmic losses which is mainly due to imperfect dielectric materials and ohmic loss occurring due to feeding mechanism and ground plane current, high radiation efficiency and increased bandwidth can be achieved with lower permittivity, where for a simple rectangular DRA, a bandwidth of $10 \%$ can be achieved for a dielectric constant of 10 or less [1]. So far DRA has been designed to be used over a wide range of frequencies and wide range of dielectric constants. [7]. When a dielectric resonator is not entirely enclosed by a conductive boundary, it can radiate and that is when it becomes an antenna. DRAs are commonly low gain antennas with a broad radiation pattern. DRAs can be designed in three basic shapes such as hemispherical, cylindrical and rectangular.

\section{COUPLING MECHANISIM OF DRA}

Feeding mechanism is an important factor in assemble and performance of DRAs because it can have a major effect on the resonant frequency and Qfactor. Power must be coupled into or out of the DRA through one or more ports and the port type and the location of the port with respect to the DRA will determine which mode will be excited and how much power will be coupled between the port and the antenna [7]. Aperture slot, coaxial probe and micro strip feed line are the various types of feeding mechanism used to excite the DRAs.

\section{RESONANT MODES}

Dielectric resonators are difficult to analyse as they have complex electromagnetic problems. The numerical investigation of the DRA antenna started as an attempt of determining the natural frequencies of various modes in an isolated DRA, without any other scattering object in its vicinity and without any excitation mechanism. It was found that the resonant frequencies are complex valued [8].

$$
S_{m, n}=\sigma_{m, n}+j \omega_{m, n}
$$

(Equation 1)

Where $\mathrm{m}$ denotes the number of azimuthal variations and subscript $\mathrm{n}$ denotes the order of appearance of modes in growing frequency direction. Assuming lossless dielectric material, the quantity in equation (2) is inversely proportional to the radiation $\mathrm{Q}$-factor of a particular mode [8] :

$$
Q_{m, n}=\frac{\omega_{m, n}}{2 \sigma_{m, n}}
$$

(Equation 2)

For a given dielectric constant $\varepsilon_{\mathrm{r}}$ and given dimensions, the numerical solution can determine the resonant frequency and the radiation Q-factor.

Dielectric resonator acts as a radiator in open space with a $\mathrm{HEM}_{11}$ mode is used for radiation. Meanwhile for DRA which is used as oscillators and filters, packaged in conducting boxes then it operates in $\mathrm{TE}_{01}$ mode. Refer to the following Figure 1. 


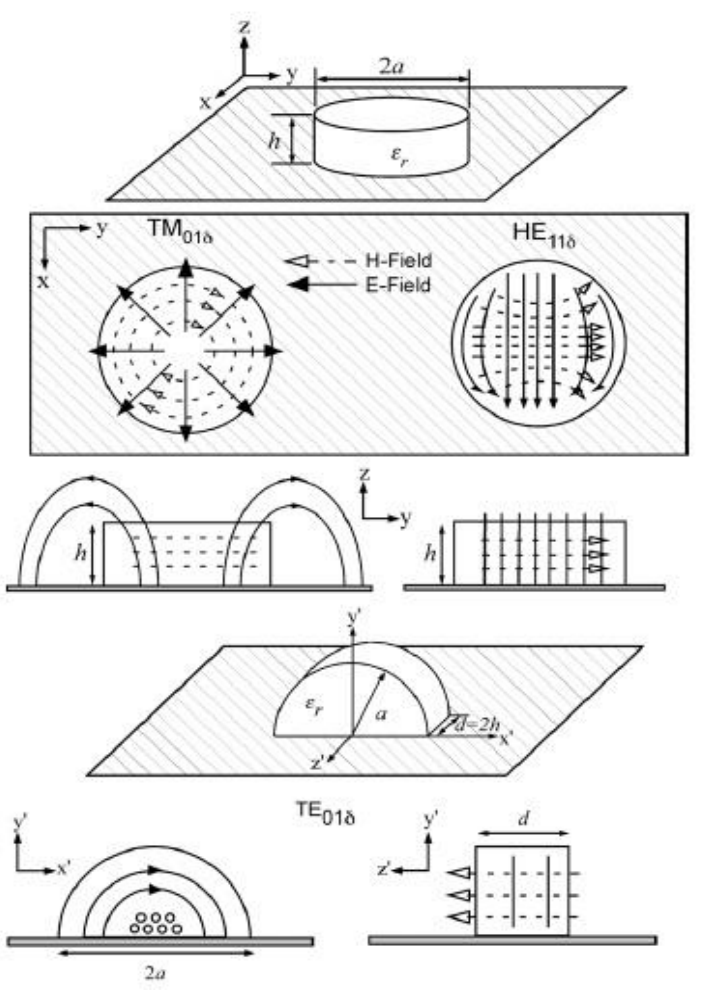

Figure 1: Sketch of the cylindrical DRA field configuration [9].

The $\mathrm{HE}_{11}$ mode of a cylindrical DRA can be achieved by offsetting the DRA from the slot centre rectangular slot as shown in Figure 2. The $\mathrm{HE}_{11}$ mode is choosen for providing broadside radiation.
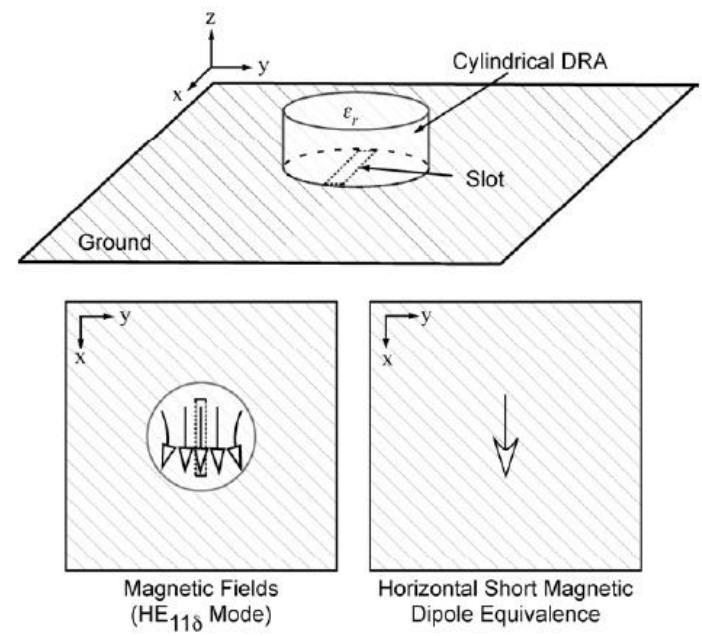

Figure 2: Slot aperture coupling to a cylindrical DRA

\section{ARRAY ELEMENTS}

Low gain and broad radiation is the typical characteristic of DRAs. Higher gain and shaped radiation pattern can be achieved with arrayed DRAs. The DRA elements can be used to form DRA array with directional radiation patterns providing enhanced antenna gain for broadband satellite communications and radar application. Studies had shown that by grouping several elements in an array the radiation parameters could be improved. The feed arrangement, the mode of operation, the spacing between elements, dimensions of the DRA elements and geometry of the DRA determine the performance of the DRA. Even though there are many advantages provided through arrayed DRA, there are also disadvantages in close spacing between elements which will result in mutual coupling between elements.

\section{MUTUAL COUPLING}

Mutual coupling (MC) or isolation is a term that describes the electromagnetic wave (EMW) interaction between antennas placed in closed proximity [2]. This interaction causes some consequences on the antennas' characteristic including distortion of radiation pattern of the array, input impedance, and gain, operating frequency, bandwidth and efficiency [9]. DRA elements which are arranged to form array will have interaction between elements due to electromagnetic wave. The level of mutual coupling depends on:

i. Spacing between elements (the mutual coupling reduces when separation between the two DRA increases)

ii. Structure, dimension (mutual coupling reduces when the height of the DRA increases) and dielectric constant of the DRA

iii. The mode of operation

iv. Fewer DRAs ( mutual coupling for fewer DRAs and the effects on the resonant frequency are smaller for fewer DRAs)

\section{ANTENNA PARAMETERS}

An antenna is a transducer that receives and transmits electromagnetic field. The definition of various parameters is necessary in order to describe the performance of an antenna. The parameters such as radiation pattern which will also cover on directivity, gain, bandwidth, beam width, side lobes, scattering parameter and polarization of waves will be discussed further. 


\section{METHODOLOGY}

Mutual coupling (MC) or isolation is a term that describes the electromagnetic wave (EMW) interaction between antennas placed in closed [2]. This interaction causes some consequences on the antennas' characteristic including distortion of radiation pattern of the array, input impedance, and gain, operating frequency, bandwidth and efficiency [9]. DRA elements which are arranged to form array will have interaction between elements due to electromagnetic wave.

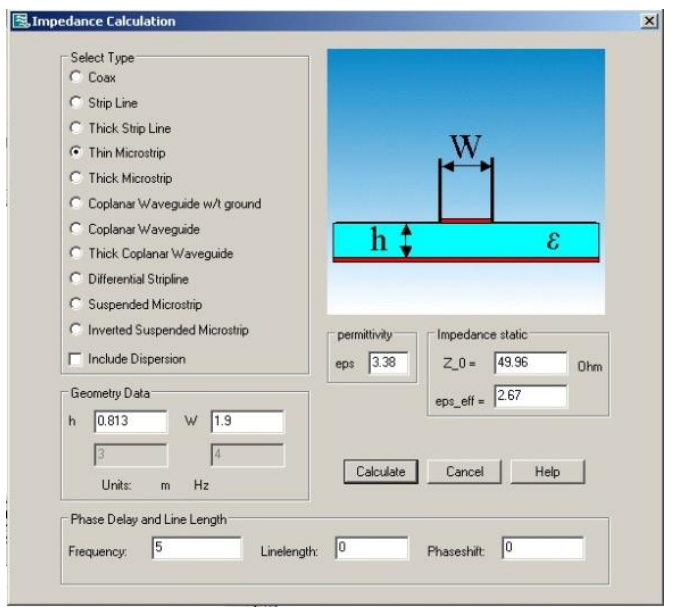

Figure 3: CST Impedance Calculation

The resonance frequency of a dielectric resonator depends on the dimensions of the resonator and its dielectric constant. Therefore, the DRA size decrease as the dielectric constant increases. The higher the permittivity, the smaller the size of DRA. The resonator frequency was calculated using Matcad 2000 Professional software. The resonator frequency was set to $5.8 \mathrm{GHz}$, the height and the diameter of the resonator for this design is $4.2 \mathrm{~mm}$ and $12 \mathrm{~mm}$ respectively. There are actually two methods of calculating the wavelength of this design. The first method is by using the epsilon effective, $\varepsilon_{\text {eff }}$ where this value is obtained from CST impedance calculator and key in the value to CST wavelength calculator as shown in Figure 4.

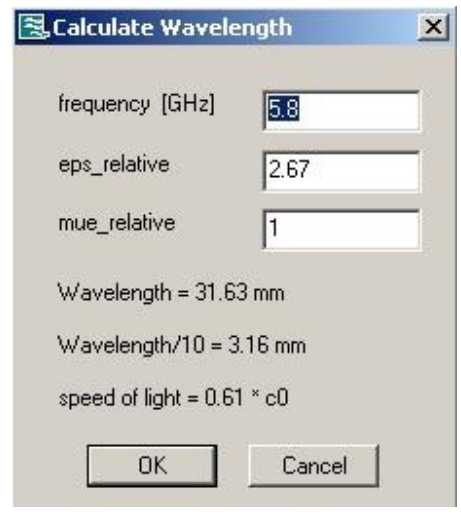

Figure 4: CST Wavelength Calculator

**The calculations were done by using Madcad 2000

Professional.

A slot coupling feeding technique was used in this project because it is the most suitable method for DRA arrays where relatively simple circuit integration [11].

The Stub Extension and Standing Wave Ratio: - A quarter-wavelength shorted stub is a special case of the stub concept used only in particular applications in microwave circuits [11].

Fabrication process: The process acquired in order to achieve the project objective. The process consists of transferring simulated design from CST to Coral draw software, creating the photo-resist pattern, etching and lastly soldering. Meanwhile dielectric resonator was done in material school. The fabricated DRA is shown in Figure 5.

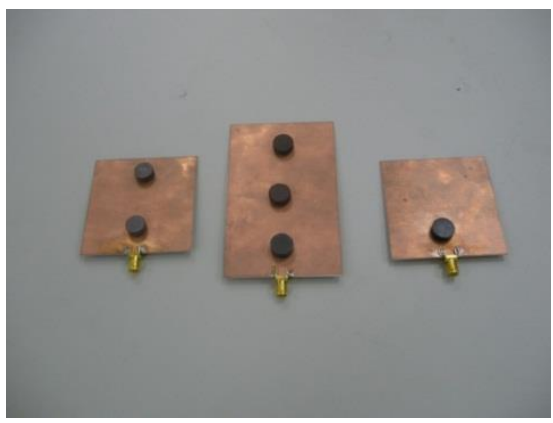

Figure 5: Aperture Coupled Cylindrical Dielectric Resonator Antenna

Measurement Process: - The procedure is done upon completing the fabrication process. The fabricated antennas are measured and the results are compared with the simulation results. The main parameter that is being measured is the return loss of the antennas, radiation pattern and gain of the antenna. 


\section{RESULT AND DISCUSSION}

\section{RESULT AND ANALYSIS OF SINGLE ELEMENT $D R A$}

First of all, the mutual coupling effect is not observed in single element DRA because it happens only when more than two DRAs exist. Other results are as explained below.

Table 1 is the summary of the simulated and measured value for retun loss, directivity (only for simulation), gain and bandwidth. Both results showed a good matching with return loss lower than $-10 \mathrm{~dB}$ and other simulation results also shows good agreement with the measured results. As of theoretical view, single DRA exhibit lower gain and low directivity as stated in [9] is been proven here, where the gain value obtained in only $4.971 \mathrm{dBi}$ and the directivity is only $8.46 \mathrm{dBi}$.

Table 1: Results of simulated and measured single element DRA

\begin{tabular}{|c|c|c|c|c|}
\hline $\begin{array}{c}\text { No of } \\
\text { Pellet }\end{array}$ & S11 & $\begin{array}{c}\text { Directiv } \\
\text { ity(dBi) }\end{array}$ & $\begin{array}{c}\text { Gain } \\
\text { (dBi) }\end{array}$ & $\begin{array}{c}\text { Bandw } \\
\text { idth }\end{array}$ \\
\hline 1 pellet & - & 8.46 & 4.971 & $2.5 \mathrm{MH}$ \\
$0.5 \lambda$ & $25.24 @ 5$. & & & $\mathrm{z}$ \\
$\begin{array}{c}\text { (simula } \\
\text { ted) }\end{array}$ & $962 \mathrm{GHz}$ & & & \\
\hline 1 & - & & & \\
pellet & $22.606 \mathrm{~d}$ & & 5.12 & $2 \mathrm{MHz}$ \\
$0.5 \lambda$ & $\mathrm{B} @$ & & & \\
(meas & $5.995 \mathrm{GH}$ & & & \\
ured) & $\mathrm{z}$ & & & \\
\hline
\end{tabular}

\section{RESULT AND ANALYSIS OF TWO ELEMENTS $D R A$}

Table 2 shows the results obtained by simulation for two DRA elements with separation distance of $0.5 \lambda, 0.75 \lambda$ and $1 \lambda$ between the elements. Thus from the results, it shows that as the separation between the element increased the return loss value, directivity and gain also increases. A drastic improvement in the gain was observed at two pellet one $\lambda$ compared with $0.5 \lambda$ and $0.75 \lambda$. One of the reasons that contribute to this phenomenon is the spacing between elements. The elements are placed with $\lambda$ distance at antinodes, voltage maximum along the transmission line, since the antinodes will repeat at every half wavelength. Another reason which strongly supported this result is the increase in the number of element as of theoretical view as stated by [12]. Large decrease in the magnitude of $S_{11}$ around the resonant frequency for two pellet $\lambda$, indicating that power is radiated well around this frequency compared to other $0.5 \lambda$ and $0.75 \lambda$.

Table 2: Results of simulated 2 pellet $0.5 \lambda, 2$ pellet 0.75 $\lambda$ and 2 pellet $1 \lambda$

\begin{tabular}{|l|l|c|c|c|}
\hline $\begin{array}{l}\text { No of } \\
\text { Pellet }\end{array}$ & \multicolumn{1}{|c|}{ S11 } & $\begin{array}{c}\text { Directivit } \\
\mathbf{y}(\mathbf{d B i})\end{array}$ & $\begin{array}{c}\text { Gain } \\
\text { (dBi) }\end{array}$ & $\begin{array}{c}\text { Bandwi } \\
\text { dth }\end{array}$ \\
\hline $\begin{array}{l}2 \text { pellet } \\
0.5 \lambda\end{array}$ & - & 6.98 & 3 & $1.9 \mathrm{Mhz}$ \\
$14.52 @ 5.90$ & & & \\
\hline $\begin{array}{l}2 \mathrm{GHz} \\
0.75 \lambda\end{array}$ & $\begin{array}{l}17.38 @ 5.96 \\
1 \mathrm{GHz}\end{array}$ & 8.08 & 3.68 & $2.3 \mathrm{Mhz}$ \\
\hline $\begin{array}{l}2 \text { pellet } \\
1.0 \lambda\end{array}$ & $\begin{array}{l}23.19 @ 5.96 \\
3 \mathrm{GHz}\end{array}$ & 9.31 & 7.181 & $6.3 \mathrm{Mhz}$ \\
\hline
\end{tabular}

The fabrication was done only for $1 \lambda$ separation distance. The results for both the simulated and measured values for return loss, directivity (only for simulation), gain and bandwidth are as shown in Table 3. As for the $S_{11}$ for both the measured and simulated value showed a large decrease in the magnitude around the resonant frequency. From this result it shows that the simulation results are reasonably agreed with the measurement.

Table 3:Results of measured 2 pellet $1 \lambda$

\begin{tabular}{|l|l|c|c|c|}
\hline $\begin{array}{l}\text { No of } \\
\text { Pellet }\end{array}$ & \multicolumn{1}{|c|}{ S11 } & $\begin{array}{c}\text { Directivit } \\
\mathbf{y}(\mathbf{d B i})\end{array}$ & $\begin{array}{c}\text { Gain } \\
(\mathbf{d B i})\end{array}$ & $\begin{array}{c}\text { Bandw } \\
\text { idth }\end{array}$ \\
\hline $\begin{array}{l}2 \text { pellet } \\
1.0 \lambda \\
\text { (measur } \\
\text { ed) }\end{array}$ & $\begin{array}{l}23.19 @ 5.9 \\
63 \mathrm{GHz}\end{array}$ & 10.1 & 7.181 & $6.3 \mathrm{Mhz}$ \\
\hline $\begin{array}{l}2 \text { pellet } \\
1.0 \lambda \\
\text { (measur } \\
\text { ed) }\end{array}$ & $\begin{array}{l}22.935 @ 5 . \\
935 \mathrm{Ghz}\end{array}$ & - & 6.14 & $5.8 \mathrm{Mhz}$ \\
\hline
\end{tabular}

\section{RESULT AND ANALYSIS OF THREE ELEMENTS $D R A$}

Table 4 shows the results obtained by simulation for three elements DRA with separation distance of $0.5 \lambda, 0.75 \lambda$ and $1 \lambda$ between the elements. Thus, from the results it is shown that as the separation between the elements increases the return loss value, directivity and also the gain values also increases. The 
higher value is obtained with a maximum gain value is at $8.619 \mathrm{dBi}$, for three pellet $1 \lambda$ with directivity of $11.4 \mathrm{dBi}$. Three pellets $1 \lambda$ has a very high gain and directivity compared to $0.5 \lambda$ and $0.75 \lambda$ because, as the $\lambda$ spacing increases, the mutual coupling interactivity also increases. The standing wave ratio micro strip short ended also contributed to the enhancement of the gain, where the maximum radiation is obtained when an element is positioned at every half $\lambda$. In this project the maximum radiation at every one $\lambda$ contributed to the mutual coupling interactivity which results in higher gain and directivity.

Table 4: Results of simulated 3 pellet $0.5 \lambda, 3$ pellet 0.75 $\lambda$ and 3 pellet $1 \lambda$

\begin{tabular}{|c|c|c|c|c|}
\hline $\begin{array}{l}\text { No of } \\
\text { Pellet }\end{array}$ & S11 & $\begin{array}{l}\text { Directiv } \\
\text { ity }(\mathrm{dBi})\end{array}$ & $\begin{array}{l}\text { Gain } \\
\text { (dBi) }\end{array}$ & $\begin{array}{c}\text { Bandw } \\
\text { idth }\end{array}$ \\
\hline $\begin{array}{l}3 \text { pellet } \\
0.5 \lambda\end{array}$ & $\begin{array}{l}- \\
13.03 @ 5.9 \\
33 \mathrm{GHz}\end{array}$ & 9.36 & $\begin{array}{c}8.56 \\
9\end{array}$ & $4.8 \mathrm{Mhz}$ \\
\hline $\begin{array}{l}3 \text { pellet } \\
0.75 \lambda\end{array}$ & $\begin{array}{l}- \\
14.88 @ 5.9 \\
45 \mathrm{GHz}\end{array}$ & 10.3 & $\begin{array}{c}7.48 \\
9\end{array}$ & $5 \mathrm{Mhz}$ \\
\hline $\begin{array}{l}3 \text { pellet } \\
1.0 \lambda\end{array}$ & $\begin{array}{l}- \\
26.07 @ 5.9 \\
48 \mathrm{GHz}\end{array}$ & 11.4 & $\begin{array}{c}8.61 \\
9\end{array}$ & 3.4Mhz \\
\hline
\end{tabular}

The fabrication was done only for $1 \lambda$ separation distance. The results for both the simulated and measured values for return loss, directivity (only for simulation), gain and bandwidth are as shown in Table 5. From the results it shows that the simulation results are reasonably agreed with the measurement.

Table 5: Results of measured 3 pellet $1 \lambda$

\begin{tabular}{|c|l|l|l|l|}
\hline $\begin{array}{c}\text { No of } \\
\text { Pellet }\end{array}$ & \multicolumn{1}{|c|}{ S11 } & $\begin{array}{c}\text { Directiv } \\
\text { ity(dBi) }\end{array}$ & $\begin{array}{c}\text { Gain } \\
\text { (dBi) }\end{array}$ & $\begin{array}{c}\text { Bandw } \\
\text { idth }\end{array}$ \\
\hline $\begin{array}{c}3 \text { pellet } \\
1.0 \lambda\end{array}$ & $-26.07 @ 5.94$ & 11.4 & 8.619 & $3.4 \mathrm{Mhz}$ \\
$\begin{array}{c}\text { (simula } \\
\text { ted) }\end{array}$ & $8 \mathrm{GHz}$ & & & \\
\hline $\begin{array}{c}3 \\
\text { pellet } \\
1.0 \lambda \\
\text { (meas } \\
\text { ured) }\end{array}$ & $\begin{array}{l}23.235 @ 5.9 \\
407 \mathrm{GHz}\end{array}$ & & 7.812 & $3 \mathrm{Mhz}$ \\
\hline
\end{tabular}

\section{RESULT AND ANALYSIS OF FOUR ELEMENTS $D R A$}

Table 6 shows the results obtained by simulation for four DRA elements with separation distance of $0.5 \lambda, 0.75 \lambda$ and $1 \lambda$ between the elements.
As for the return loss it increases with the separation distance. The gain obtained are $0.8898 \mathrm{dBi} 6.913 \mathrm{dBi}$ and $4.917 \mathrm{dBi}$ for separation distance of $0.5 \lambda, 0.75 \lambda$ and $1 \lambda$ respectively. Meanwhile the directivity is $6.93 \mathrm{dBi}, 10.1 \mathrm{dBi}$ and $8.653 \mathrm{dBi}$ for separation distance of $0.5 \lambda, 0.75 \lambda$ and $1 \lambda$ respectively. It can be concluded that the simulated design for these four pellets with separate element spacing do not agree with the theoretical observation [12] since we observed the value of gain and directivity which is supposed to increase with the number of element is not seen here.

Comparison between the results obtain with two pellets DRA elements, three pellets DRA elements and four pellets DRA elements shows that the mutual coupling gives a negative effect on two and four pellets DRA elements compared to positive effect on three pellets DRA elements. This could be due to incompatibility or unsuitability of this design for two and four pellets because this study is based on the distance between the slot to slot and not done from DRA to DRA.

Table 6: Results of simulated 4 pellet $0.5 \lambda$, 4 pellet 0.75 $\lambda$ and 4 pellet $1 \lambda$

\begin{tabular}{|l|l|c|c|c|}
\hline $\begin{array}{l}\text { No of } \\
\text { Pellet }\end{array}$ & \multicolumn{1}{|c|}{ S11 } & $\begin{array}{c}\text { Directivi } \\
\text { ty(dBi) }\end{array}$ & $\begin{array}{c}\text { Gain } \\
\text { (dBi) }\end{array}$ & $\begin{array}{c}\text { Band } \\
\text { width }\end{array}$ \\
\hline $\begin{array}{l}4 \text { pellet } \\
0.5 \lambda\end{array}$ & $\begin{array}{l}- \\
8.07 @ 5.9 \\
06 \mathrm{GHz}\end{array}$ & 6.93 & 0.8898 & 0 \\
\hline $\begin{array}{l}4 \text { pellet } \\
0.75 \lambda\end{array}$ & $\begin{array}{l}16.36 @ 5 . \\
944 \mathrm{GHz}\end{array}$ & 10.1 & 6.913 & $\begin{array}{c}6.7 \mathrm{MH} \\
\mathrm{z}\end{array}$ \\
\hline 4 pellet & - & 8.653 & 4.719 & $3.3 \mathrm{MH}$ \\
$1.0 \lambda$ & $\begin{array}{c}23.39 @ 5 . \\
94 \mathrm{GHz}\end{array}$ & & & $\mathrm{z}$ \\
\hline
\end{tabular}

\subsection{CONCLUSIONS}

The investigations on the radiation patterns clearly illustrated that repel occurs between the four DRA element's radiated electromagnetic wave. It is clear that as the number of elements increases, it is actually causing the electromagnetic interaction to repel and this phenomenon actual produce effect on the performance of an array in terms of directivity and the gain as observed.

\section{ACKNOWLEDGMENTS}

The authors acknowledge the tangible and intangible supports from Jabatan Pengajian Politeknik \& Kolej Komuniti, Kementerian Pendidikan Tinggi Malaysia, Politeknik Seberang Perai and Politeknik Balik Pulau 


\section{REFERENCES}

[1] A.Petosa, A. I., Y.M.M.Antar, D.Roscoe, M.Cuhaci (1998). Recent Advances in Dielectric Resonator Antenna Technology. IEEE Antennas and Propagation Magazine, 40(3), 35-48.

[2] Chi-Yuk Chiu, C.-H. C., Ross D. Murch,Corbett R. Rowell (2007). Reduction of Mutual Coupling Between Closely-Packed Antenna Elements. IEEE Trans. Antennas Propag., 55(6), 1732-1738.

[3] A.Petosa, N., Simons, R.Shiusansian, A.Ittipiboon, M.Cuhaci (2000). Design and Anaysis of Multisegment Dielectric Resonator Antennas. IEEE Trans. Antennas Propag., 48(5), 738-742.

[4] M.W.McAllister, S. A. L., G.L. Conway (1983). Rectangular Dielectric Resonator Antenna. Electronics Letters, 19(6), 218-219

[5] M.W.McAllister, S. A. L. (1984). Resonant Hemispherical Dielectric Antenna. Electronics Letters, 20(16), 657-659.

[6] Balanis, C. A. (2005). Antenna Analysis and Design (3 ed.): John Wiley and Sons.

[7] Petosa, A. (2007). Dielectric Resonator Antenna Handbook: Artech House, Inc.

[8] D.Kajfez, A. A. K.(1989) Dielectric Resonator Antenna- Possible Candidate for Adaptive Antenna Arrays.

[9] H. Fayad, P. R. (2009). Mutual Coupling Between an Pair of Identical Beam Steering Dielectric Resonator Antennas. Progress in Electromagnetic Research, 14, 23-44.

[10] S.A. Long, M. W. M., L.C.Shen (1983). The Resonant Cylindrical Dielectric Cavity Antenna. IEEE Transactions on Antennas and Propagation, 31(3), 406-412.

[11] M. F. Ain, Y. M. Q., Z. A. Ahmad, M. A. Zakariya, M. A. Othman, A. A. S., A. Othman, \& Abdullah, S. D. H. a. M. Z. (2010). A Novel $5.8 \mathrm{GHz}$ Array Dielectric Resonator Antenna Electromagnetic Research, 15, 201-210.

[12]Z.Wu (2003). Dielectric Resonator Antenna Arrays, Chapter 9 in Dielectric Resonator Antennas: Research Studies Press. 